\author{
V International Forum on Teacher Education
}

\title{
Cognitive Modelling of the Socialization Process as a Digital Transformation Trend in Higher Education
}

\author{
Valeria Sh. Maslennikova*(a), Vera M. Zhurakovskaya (b), Vera A. Bogovarova \\ (c), Roman E. Moiseev (d) \\ (a) "Institute of Pedagogy, Psychology and Social Problems", Kazan, Russia \\ (b) Academy of Social Management of Moscow region, Moscow, Russia \\ (c) Institution of Higher Education "University of management "TISBI", Kazan, Russia \\ (d) Kazan National Research Technical University named after A.N.Tupolev, Kazan, Russia
}

\begin{abstract}
The relevance of the study of this problem is due to the intensive implementation of new information technologies and various electronic courses that contribute to the introduction of digitalization in the educational system. According to the regulatory documents, the purpose of digitalization of the educational system is to ensure a broad access to information and digital resources, and the use of digital technologies in the educational process. In this regard, this article focuses on the identification and disclosure of the purpose and objectives of digitization in the education system, the implementation of the principle of organization of mastering of the optimally required knowledge, a particular algorithm, contributing to the development and transmission of knowledge by means of individual internal and external instruments of knowledge representing the cognitive organization of a personality. The leading method in the study of this problem is the interdisciplinary analysis of scientific literature, which allowed to reveal the essence of the digitalization of the educational process, optimization of the method of cognitive modeling in the educational process in order to develop internal instruments of knowledge of students; theoretical modeling, which allowed to structure the planning process of educational activities in higher education. The article reveals the changes determined by the new socio-cultural and economic situation of digital development, substantiates the new formats of collaboration and learning built around the student, requiring digital literacy teachers and responsibility of students for the quality of their education. The article is focused on the adaptation of teachers to the new conditions of professional activity in the field of education in the conditions of digitalization.
\end{abstract}

Keywords: digital education, digital educational environment, digital technologies, digital literacy, cognitive modeling.

(C) 2019 Valeria Sh. Maslennikova, Vera M. Zhurakovskaya, Vera A. Bogovarova, Roman E. Moiseev

*Corresponding author. E-mail address: maslennikova_valeriya@mail.ru 
This is an open access article distributed under the terms of the Creative Commons Attribution License (CC BY 4.0), which permits unrestricted use, distribution, and reproduction in any medium, provided the original author and source are credited.

Published by Kazan Federal University and peer-reviewed under responsibility of IFTE-2019 (V International Forum on Teacher Education)

\section{Introduction}

\subsection{Actuality of the phenomenon "digitalization"}

In modern conditions of society development there is an intensive discussion of the nearest digital future, which comes into its own in all spheres of life. The Federal programme "Digital economy of the Russian Federation" (2017) (Programme; 2017); (State program, 2013-2020) notes that "the number of personnel training and compliance of educational programs with the needs of the digital economy is insufficient", that "there is a shortage of personnel in the educational process at all levels of education." The implementation of new information technologies in the educational system, various electronic courses contribute to the introduction of digitalization in education.

In the pedagogical sciences, there are new concepts and terms, such as digital education, digital learning environment, digital technologies, digital literacy, etc. (Kudlaev, 2018); (Polupan, 2018) which become relevant to the question of the educational paradigm shift for digital education actively restricts "analog".

\subsection{Major goal and tasks of digitalization}

According to the some regulatory documents (State program, 2013-2020); (Ainoutdinova, 2017); (Maslennikova, 2017) the goal of digitalization of the educational system is to ensure a broad access to information and digital resources and the use of digital technologies in the educational process.

To achieve this goal, educational organizations are faced with the following tasks of digitalization: training and professional self-development of teachers on the use of digital technologies in educational activities; implementation of digital technologies in the educational process; provision for collective use of digital resources and access to them in the cloud resources; to increase the level of motivation for the professional use of digital technologies by teachers and students; to create innovative conditions for development through the introduction of digital technologies; to provide information and consulting services on the use of digital and cloud technologies with unlimited resources; to accumulate, systematize and disseminate information on the use of digital and cloud technologies by an educational organization; to introduce digital and cloud technologies into the educational process (Baehr, 2013); (Castells, 2009); (Maslennikova, 2017).

\subsection{Need for modeling the educational process}

Therefore, according to the implementation of the goal of effective management of the educational system development via means of modern digital technologies, it is necessary to build virtual models. The model is based on mathematical objective laws presented as a system of algorithms with direct and inverse connections. 
New formats of collaboration and learning, created within a student, will require students to take greater responsibility for the quality of their education. In the digital education there is a decrease on the value of professors as "transmitters of knowledge" and increase on their value as maintainers of individual student learning. Such changes in educational formats will require teachers to develop new specific competencies, including those related to digital technologies.

\subsection{Relevance of the teachers' activities in accordance with digitalization}

The emergence of new psychological contexts (social networks, blogosphere, virtual worlds, etc.) is reflected in the process of the emergence of new phenomena (Internet addiction, multitasking, selfism, etc.) and the emergence of new forms of development of relationships with other people, including negative and aggressive behavior (flame, flood or spam, trolling, catersto, cyberbullying). Of course, in the process of innovative pedagogical activity, the following factor should be taken into consideration. For the modern pedagogical activity of the system of higher education largely depends on the extent to which teachers and the administration itself possess digital technologies and digital information, how quickly they can analyze and process it on their own or using information technologies, as well as bring it to the final user - the students and their legal representatives (Beacham, 2014); (Kale, 2014).

This means that the activities of teachers should focus on the integration of automation and placement of processes in order to make them more effective, through the redistribution of resources in the real and virtual environment of the educational organization.

Thus, fulfilling the requirements of the time and taking into account the request of the state to increase the output of specialists in the field of digital economy, it is necessary to solve the problem on the national level - to achieve universal digital literacy. At the same time, the formation of digital literacy should be given special attention along with the reader's, mathematical and natural-scientific literacy. All in all, the education system at all levels, beginning from school to higher education, should be seriously improved. And of course, it is necessary to develop training programs for people of all ages.

As technological changes take place, new substantive academic issues will be raised, which, in their turn, will require new technological solutions. Universities should be concerned not so much with promoting technological innovations, but with creating their own electronic resources and applications, as with developing their educational programmes at the expense of existing infrastructure.

Advanced data analysis techniques will open up new ways of understanding teaching and learning processes. The use of complex data analysis will make it possible t realize flexible changes in the course programme, depending on the difficulties encountered by students in the development of educational materials, and will also act as a means of feedback for teachers and an additional means of assessing academic performance (Villa, 2017).

\section{Methodological framework of the research}

\subsection{Planning as a key mechanism for students' socialization and modeling the educational} process

Planning plays a key role in the search for effective means and mechanisms of the process of socialization of students in higher education. The planning process of pedagogical activity in the process of socialization of students is based on the definition of the system and the order of functioning of all personal instrumental and methodological tools used to achieve the goals. Planning technology is a set of 
activities (operations) to develop a plan, which acts as a pre-planned procedure, the sequence of the implementation of any program of work. In order to implement effective planning of pedagogical activity in the process of socialization with the help of modern digital technologies it is possible to build a cognitive virtual model. The model is based on objective laws presented as a system of algorithms with direct and inverse links.

In the process of planning, several elements are determined: goals; objectives; main directions; technologies; diagnostic tools for determining time indicators; officials responsible for the implementation of specific areas and sections; a variety of resources: (scientific, educational, organizational, methodological, personnel, material and financial), etc.

Analysis of planning studies allows us to formulate the common aspects of pedagogical modeling of the planning process of socialization of students : the disclosure of the objectives of creating conditions for the individual development of each student; the content of different directions and pedagogical technologies to achieve these goals; the timing of their implementation; management functions and organization of leadership; functions of execution; various resources.

The structure of traditional planning can also be divided into several levels of organization of the socialization process. General University events reflecting mass forms are on the first level, on the second group - forms, events organized within the collective of academic groups, public student organizations.

At the third level, individual personally-oriented work is carried out, contributing to professional and personal development.

The main purpose of planning is to create conditions for the implementation of the individual development vector of each student on the basis of pedagogical design of the most effective technologies of pedagogical influence.

The definite factors, influencing the content of planning of pedagogical activity with students, are allocated:

- external, reflecting the current state of socio-political, socio-economic and cultural life of the country, region;

- internal, reflecting traditions and prospects of innovative development of the professional educational organization and creation of conditions for creative and successful development of students (Maslennikova, 2017).

\subsection{Pedagogical design and project-developing approach as a basis for students' socialization}

On the basis of various research it was stated that planning of pedagogical process of socialization of students is carried out effectively on the basis of the design and project-developing approach and its principles promoting realization of opportunities of the separate professional educational organization to predict and anticipate mentally development of pedagogical events and situations, to provide the organization of system of educational activity for providing conditions of professional and personal development of each personality of the student, based on the findings of the analysis of the diagnosis of the previously carried out pedagogical process.

Planning the process of students' socialization reflects the function of pedagogical management which is a set of algorithmic actions to implement the content, forms, methods of organization of pedagogical activity and the expected timing of its implementation.

Development of the content of planning on the basis of the project-developing approach is carried out taking into account the principles of implementation of the project-developing approach to planning the 
process of socialization of students in the form of targeted content planning projects aimed at the formation of general cultural, social, professional competencies of future professionals. It embraces:

- continuity of pedagogical activity in the conditions of educational process and social and cultural activity and outside the educational organization;

- consistency and coordination of all structural units: departments, departments, faculties, student organizations, group curators, etc.;

- variability of content: the presence of a variety of projects, programs that take into account the interests, opportunities and professional specialization and contribute to the holistic development of students.

-innovation: development and testing of original author's methods and technologies of the process of students'socialization, including project technologies;

- continuous pedagogical monitoring of the effectiveness of pedagogical work.

The main directions of the content of the process of socialization of students are: cultural and moral, civil-patriotic, professional and labour education.

The basis of the development and modeling of the plan of pedagogical activity is the selfdevelopment of internal tools of knowledge of teachers, the ability to independently design and modify the base of their own knowledge by external and internal tools of knowledge, to navigate in the information space, to develop analytical, critical and creative thinking.

\subsection{Cognitive modeling as a special way of activity planning}

In the process of cognitive modeling of teachers' socio-pedagogical activity planning, the type of thinking changes qualitatively: concrete-figurative type is replaced by abstract-logical and further theoretical-research, contributing to the formation of skills to adapt, flexibly and quickly respond to rapidly changing conditions of professional activity and everyday life.

Becoming the subject of information management, the process of socialization of students, its parts and modules, the program at all stages of development of the plan of socio-pedagogical activity, the mode of obtaining and processing data, the type of their presentation (visual, audio, text, etc. information), the personality of the teacher develops an individual way of organizing socio-pedagogical activities that meets its qualities, abilities, motivation, as well as the objective characteristics of the chosen type of professional activity. It is possible not only to visualize the information obtained, but also to implement recommendations for decision-making, which users can get in any form of cognitive model and both in graphical and textual form.

The following technological organization of the educational process is due to the algorithmic nature of human activity as the most natural and convenient for human activity.

But it should be noted that in the cognitive planning of pedagogical activity the nature of the activity is changing: the teacher not only uses the technology to solve the finished professional problem, but also determines the feasibility, the need for the proposed solutions in the future educational activities, based on the results of monitoring the quality of pedagogical work.

A synergistic effect in this case is the following crucial aspects:

- obtaining a large amount and variety of necessary information;

- $\quad$ ability to act at risk, with "cautious courage" in decision-making;

- activity of mental actions of everyone responsible for social and educational activities.

Integrative criterion of quality of the developing educational environment created on the basis of 
the design and developing approach is possibility of this environment to provide to all subjects set of conditions for effective personal self-development. Self-development determines the effectiveness of the process of self-improvement, and it results in the degree of self-realization of a person, causing its development not only as a professional, but also as an individual in all its diversity.

\section{Methods of research}

The following methods were used in the research: theoretical (interdisciplinary analysis of scientific literature; synthesis; concretization; generalization; analogy method; modeling); empirical (study of the experience of educational organizations, normative and educational documentation; pedagogical observation);

\section{Question for discussion}

The study of psychological and pedagogical literature allows us to state the absence of special studies on the problem of cognitive modeling of pedagogical activity in the process of socialization of students in higher education in the context of digitalization. However, the process of digitalization of education in Russia (Kudlaev, 2018), interactive intellectual environment as a digital technology of continuous education( Polupan, 2018), educational environment: from modeling to design (Villa D\&Dorsey,J., 2017) is revealed in the research of the scientists, mentioned above.

\section{Results}

In the process of analysis of research on the studied problem, it was found out that the basis of the development of any content of the educational course, the programme of socialization of students, learning technology, the important principle is not "filling" the student with a large amount of content of educational, information material, and the principle of organization of mastering the optimal required set of knowledge, the implementation of a certain algorithm that promotes the development and translation of knowledge by means of individual internal and external tools of knowledge, representing the cognitive organization of the individual.

It should be noted that based on the essential characteristics of the design and project-developing approach, the planning of the pedagogical process and its features are determined by the following factors:

- planning is designed to create conditions for the effective development of the personality of the future specialist;

- the process of planning on the basis of forecasting, the purpose, objectives and result of innovative pedagogical activity is proved;

- the planning is aimed at the establishing certain terms of innovative pedagogical activity of teachers to achieve the expected results of the predicted state;

-the programming of algorithmic actions and the definition of the circle of organizers to achieve the targets of pedagogical activity is considered as an integral element of the implementation of the content of planning.

Finally, the effectiveness of the implementation of planning depends on the motivational readiness of the subjects of the socialization process to implement the design and development activities.

So that we may conclude that cognitive modeling of the educational process implies thorough planning, creating a definite algorithm and its step-by-step implementation in the studying process. 


\section{Discussions}

\subsection{Comparative analysis of Russian and German systems of higher education}

It is useful to study the experience of implementing advanced tools in educational systems that work in a logic similar to the Russian one. Thus, higher education in Germany is very similar to the system of higher education in Russia. From a historical point of view, we can say that the Russian system of higher education was copied from the German in the early XIX century. Since then, these systems have developed independently and with significant national characteristics. Thus, the Russian universities are dominated by a system of strict educational plans, which do not exist in German universities, but operate in professional technical schools (Hochschule).

An important structural similarity between the Russian and German education systems is the funding of universities mainly from the state budget at various levels. It is this property that determines the strategy of universities and does not allow them to copy the strategies of private universities in the United States, funded by donations from graduates and personal funds of students.

The foresight study of the German forum on the prospects of digitalization in higher education (Hochschulforum Digitalisierung) can help to assess the impact of digital technologies on the strategies of German universities. A systematic view on digitalization, taking into account both technological perspectives and modern administrative and organizational reality, makes this study particularly interesting for employees (teaching staff, administrators of the Russian higher education system.

In the context of serious differences in the structure and specialization of different universities, it is impossible to use a single, standardized method of digitalization of higher education. The development of digital education in different universities should correspond to the specific features of the universities, their students and partners. Moreover, the development of digital education will further strengthen the trend towards differentiation and specialization of universities, the search for effective means and mechanisms of the educational process (Rokenes, 2014); (Maslennikova, 2017).

\subsection{To the question of students' mass digitalization and opportunities for self-study}

It was found out that the importance of attending one and a half hour lectures in the learning process is nowadays sufficiently reduced, because the student can independently receive the necessary information and be involved in the process at a convenient time for him. The learning process becomes more flexible, responding to the individual needs of the student.

At the same time, some of the researchers (Kudlaev, 2018), (Polupan, 2018) note that such training deprives the student of personal communication with the teacher, and most importantly, even if he can digest a huge amount of information, it turns into the so-called "clipped" knowledge, without systematization and analytical understanding.

The relevance of the study is that the formation and development of a new "network generation" reflect the changes determined by the new socio-cultural situation of development. There are changes in higher mental functions (memory, attention, thinking, perception, speech), causing the development of individual tools of knowledge. Intensification of the use of the Internet as a cultural tool for solving various problems in new rather than traditional ways and contribute to the emergence of changes in the culture of social practices (modes of activity). There are changes in the mechanisms of personality formation (identity, status, reputation, accumulation of social capital, personal and individual characteristics). 


\section{Conclusion}

Becoming the subject of management of the process of socialization of students, its parts and modules, the program at all stages of development of the plan of socio-pedagogical activity, mode of data acquisition and processing, the type of their presentation (visual model, audio, text, etc. information), the teacher develops an individual way of organizing socio-pedagogical activity that meets its qualities, abilities, motivation, as well as objective characteristics of the chosen type of professional activity. It is possible not only to visualize the information obtained in the form of cognitive modeling, but also to implement recommendations for decision-making, which users can get in any form of cognitive model and both in graphical and textual form.

\section{References}

Ainoutdinova, I.N., Khuziakhmetov, A.N., Tregubova, T.M. (2017). Advantages and Disadvantages of Distance education for University Students in Russia. Modern Journal of Language Teaching Methods, 7 (9/2), pp. 82-86.

Baehr J. (2013) Educating for Intellectual Virtues: From Theory to Practice. Journal of Philosophy of Education, 47, 2.

Beacham, N. \& McIntosh, K. (2014). Student teachers' attitudes and beliefs towards using ICT within inclusive education and practice // JORSEN, 14 (3), pp. 180-191.

Castells, M. (2009). The Rise of the Network Society. The Information Age: Economy, Society and Culture / Vol. 1 (2nd ed.) - Malden: Wiley-Blackwell Publishing. - Pages 656.

Kale, U. \& Goh, D. (2014). Teaching style, ICT experience and teachers' attitudes toward teaching with Web 2.0 // Education and Information Technologies, 19 (1), pp. 41-60.

Kudlaev, M.S. (2018) The process of digitalization of education in Russia. Molodoj ucheny $j$ - Young scientist, 31, 3-7. URL https://moluch.ru/archive/217/52242/ (accessed: 02.02.2019).

Polupan, K.L. (2018) Interactive intellectual environment - digital technology continuing education. Vi sshee obrazovanie v Rossii - higher education in Russia, 27, 11.

Programme "Digital economy of the Russian Federation" was approved by the order of the Government of the Russian Federation dated 28.07.2017 № 1632-p.

Rokenes, F.M. \& Krumsvik, R.J. (2014). Development of Student Teachers' Digital Competence in Teacher Education - A Literature Review // Universitetsforlaget: Nordic Journal of Digital Literacy (Special Issue), Vol. 9, Nr. 4-2014, pp. 250-280.

State program of the Russian Federation "development of education" for 2013-2020. URL:http://new.volsu.ru/upload/medialibrary/809/Proektirovanie education 2013-2020.pdf

Valeriya Sh. Maslennikova, Tatiana M. Tregubova, Anvar N. Khuziakhmetov, Ramis R. Nasibullov. The Problem Of Innovative Development Of The Modern Professional Education In Russia // IFTE 2017 III International Forum on Teacher Education. /European proceedings of social \& behavioral sciences EpSBS. - 2017, № 3. - 960p. - Pp.508-517

Villa, D. \& Dorsey, J. (2017). The State of Gen Z 2017: Meet the Throwback Generation: White Paper / Research by: The Center for Generational Kinetics, Austin, Texas, USA. - Pages 30. 